\title{
La visión del mundo animal en la España del siglo XVII: El Bestiario de Covarrubias
}

\author{
Arturo Morgado García \\ Universidad de Cádiz \\ arturo.morgadogarcia@uca.es
}

Recibido: 16 de diciembre de 2009

Aceptado: 13 de octubre de 2010

\section{Resumen}

Durante el siglo XVII el mundo animal era visto todavía bajo una perspectiva moralizante y simbólica, en la cual los animales eran equiparados con los vicios y virtudes humanos, lo que era una herencia de las concepciones medievales iniciadas con el Fisiólogo. Este trabajo pretende analizar la visión del mundo animal en la España del momento, tomando como base el Tesoro de la Lengua Castellana (1611) de Sebastián de Covarrubias.

Palabras clave: Historia cultural de los animales, España, siglo XVII, historia de la cultura, literatura emblemática, Sebastián de Covarrubias.

\section{The animal world vision in $17^{\text {th }}$ Century Spain: The Covarrubias Bestiary}

\begin{abstract}
In the seventeenth century the animal world was still conceived under a moralistic and symbolic perspective. Animals were matched with human vices and virtues, a legacy of medieval conceptions initiated with the Physiologus. This paper explores the animal world view in seventeenth century Spain, based primarily on the famous Spanish Dictionary Tesoro de la Lengua Castellana (1611), by Sebastián de Covarrubias.
\end{abstract}

Key words: Cultural History of Animals, Spain, $17^{\text {th }}$ Century, Cultural History, Emblematic Literature, Sebastián de Covarrubias.

\section{Referencia normalizada}

Morgado García A. (2011). "La visión del mundo animal en la España del siglo XVII: el Bestiario de Covarrubias". Cuadernos de Historia Moderna, Vol 36.: pp. 67-88

\section{Sumario:}

1. La Historia cultural de los animales, 2. Tres visiones del mundo animal, 3. Un modelo de visión simbólica: la obra de Covarrubias, 4. Conclusión. 


\section{La Historia Cultural de los animales}

Aparentemente, constituye un contrasentido unir en un mismo término la referencia a cultura, vocablo íntimamente asociado a la experiencia humana, con el mundo animal. Pero hay que superar esta dualidad: a lo largo de la historia, el hombre ha tenido una determinada experiencia y ha desarrollado una serie de representaciones acerca de la naturaleza, representaciones y experiencias que, como cualquier producto histórico, cambian a lo largo del tiempo, y que constituyen un elemento digno de analizar y de estudiar. Esta historia cultural de los animales (Cultural History of Animals, aunque los franceses prefieren utilizar el término zoohistoria) ${ }^{1}$ tiene unos objetivos distintos a los de la tradicional historia natural: si ésta tenía como principal preocupación el análisis de la evolución de la percepción científica de los animales a lo largo del tiempo, transmitiendo subliminalmente una concepción whig y positivista ${ }^{2}$, en la cual había un especial interés por poner de relieve los aciertos (el fetichismo del precedente) y los errores, olvidando en muchas ocasiones que la misma historia natural es un producto histórico; la historia cultural de los animales, en cambio, tal como es concebida actualmente, enfatiza el carácter evolutivo y cambiante de las percepciones y las representaciones, muy en línea con las ideas postmodernistas que imperan actualmente en las ciencias sociales.

En el mundo anglosajón los denominados Animal Studies, Human-Animal Studies (HAS) o Anthrozoology constituyen una disciplina independiente, con la misma dignidad que pudieran tener los Gender Studies, la Social History, la Economic History o la Cultural History. De hecho, muy recientemente, la prestigiosa editorial oxoniense Berg Publishers ha publicado una A cultural history of animals (2007) en seis volúmenes a través de cuya lectura podemos apreciar cuales son los temas predominantes: la domesticación de los animales, sus representaciones iconográficas, los parques zoológicos, su papel en deportes y espectáculos, los planteamientos filosóficos acerca de ellos... como es natural en este tipo de trabajos concebidos en el mundo angloparlante, la mayor parte de los autores procede del ámbito académico británico y estadounidense, con algunos especialistas franceses que ponen la necesaria nota continental ${ }^{3}$.

Naturalmente, este esfuerzo no ha surgido de la nada. Los animales siempre han tenido cabida en estudios arqueológicos, literarios y artísticos, y los bestiarios medievales han constituido, tradicionalmente, un campo privilegiado para ello. Pero este nuevo enfoque, centrado sobre todo en la representación que el hombre tiene de la naturaleza, probablemente tenga una de sus primeras manifestaciones importantes

${ }^{1}$ De hecho, es el término que utiliza una pionera en estas cuestiones, Dolores Carmen Morales Muñiz. Vid. "Zoohistoria: reflexiones acerca de una nueva disciplina auxiliar de la ciencia histórica", Espacio tiempo y forma. Serie III, Historia Medieval, 4, 1991.

${ }^{2}$ Así, un autor tan solvente como López Piñero, despacha la obra de Jerónimo Cortés Libro y tratado de los animales terrestres y volátiles (1613), considerándola "una mera reunión de materiales de segunda mano, realizada con muy escaso rigor" (LOPEZ PIÑERO, J. M., Ciencia y técnica en la sociedad española de los siglos XVI y XVII, Barcelona, 1979).

${ }^{3}$ Interesan para la época moderna BOEHRER, B. (dir.), A cultural history of animals in the Renaissance, y SENIOR, M. (dir.), A cultural history of animals in Enlightenment, tomos 3 y 4 de la serie. 
con la obra de Keith Thomas, Man and the natural World: changing attitudes in England 1500-1800, publicada por primera vez en 1983, y que nunca ha sido traducida al castellano, y en la que se planteaba cuál era la actitud ante la naturaleza en la Inglaterra moderna, que experimenta una fuerte evolución desde un absoluto antropocentrismo a una relación algo más igualitaria cuyos primeros exponentes podemos apreciar en el siglo XVIII. La antorcha de Thomas ha sido recogida en la actualidad por Erica Fudge, lectora en Literary and Cultural Studies en la universidad de Middelsex en Londres, y autora de una amplísima producción, centrada básicamente en los siglos XVI y XVII ${ }^{4}$.

En el mundo académico francés, por su parte, fueron los medievalistas los que jugaron el papel pionero ${ }^{5}$. Podríamos señalar el trabajo de Jean Claude Schmitt (aunque no le interesaban tanto los animales como la religiosidad) Le Saint Lévrier. Guinefort, guérisseur d'enfants depuis le XIIIe siècle (1979, trad, esp. 1984); al que pocos años después se uniría la obra del también medievalista Robert Delort Les animaux ont une histoire (1984), que fue realmente el gran impulsor de la zoohistoria en el país vecino y que tendría un gran éxito mediático, hasta el punto de haber dado origen a una serie de televisión. El siguiente hito vendrá dado por la figura de Eric Baratay, algunas de cuyas primeras obras fueron L' eglise et l'animal (France, XVIIe-XXe siécle)(París, 1996), o Zoo: Histoire des jardins zoologiques en Occident (XVIe-XXe siécle)(París, 1998), esta última en colaboración con Hardouin Fugiet. Con el fino olfato que tradicionalmente han manifestado siempre los franceses ante las nuevas líneas de investigación, ya en 1997 el mismo Baratay dirigía un número monográfico de la revista Cahiers d' Histoire dedicado a los animales domésticos, y en cuya introducción señalaba cómo la historia de los animales, nacida tímidamente en la década de 1980, aún constituía un terreno prácticamente virgen, no tanto para el mundo antiguo y medieval, pero sí para la época moderna, $y$, especialmente, contemporánea ${ }^{6}$. Aunque últimamente hay un creciente interés por parte de los especialistas en la época moderna, vengan de la historia, la literatura, o la filosofía, como revelan la celebración del coloquio organizado por el Centre de Recherches sur le XVIIe siécle européen de la Universidad de Burdeos y dirigido por Charles Mazouer, L'animal au XVIIe siécle (2003), o el hecho de que el último número de la revista Dixhuitieme siécle (2010) esté dedicado al mundo animal. Quizás el representante galo de la historia de los animales más conocido en España sea Michel Pastoureau, que muy recientemente ha publicado L'ours. Histoire d'un roi déchu (2007), trabajo, que, en nuestra opinión, constituye todo un modelo de lo que debe ser la historia cultural de los animales?

${ }^{4}$ Podríamos destacar Perceiving Animals, Humans and Beasts in Early Modern English Culture, Urbana and Chicago, University of Illinois Press, 2002, y Brutal Reasoning: Animals, Rationality and Humanity in Early Modern England, Ithaca, Cornell University Press, 2006; así como la coordinación de obras de carácter colectivo tales Renaissance Beasts: Of Animals, Humans, and Other Wonderful Creatures, Urbana and Chicago, University of Illinois Press, 2004, y At the Borders of the Human: Beasts, Bodies and Natural Philosophy in the Early Modern Period, Londres, Macmillan, 1999.

${ }^{5}$ PASTOUREAU, Michel, Una historia simbólica de la Edad Media Occidental, Buenos Aires, Katz Editores, 2006. De hecho, Robert Fossier dedica un extenso capítulo a los animales en su síntesis Gentes de la Edad Media, Madrid, Taurus, 2007.

${ }^{6}$ BARATAY, Eric, y MAYAUD, Jean-Luc, « Avertissement », Cahiers d'histoire, 42-3/4, 1997.

${ }^{7}$ PASTOUREAU, Michel, El oso. Historia de un rey destronado. Barcelona, Crítica, 2009. 
A pesar de estos destacados ejemplos franceses, la línea dominante en los Animal Studies viene marcada por el mundo anglosajón, donde se ha institucionalizado por completo como línea historiográfica independiente. En primer lugar, a través de institutos de investigación, como el Centre for-Human Animal Studies (NZCHAS) ubicado en la Universidad de Canterbury de Nueva Zelanda, y a cargo de Annie Potts $^{8}$ y Philip Armstrong9. Un segundo foco viene dado por el British Animal Studies Network, amparado por el Arts and Humanities Research Council del Reino Unido, y dirigido por Erica Fudge, a quien ya nos hemos referido con anterioridad. En Estados Unidos, por su parte, habría que destacar el Ecological and Cultural Change Studies Group ubicado en la universidad estatal de Michigan, dirigido por Thomas Dietz, y cuya figura principal, al menos para los historiadores, es la socióloga Linda Kalof, autora de Looking at Animals in Human History (Londres, Reaktion, 2006), y, en colaboración con la también socióloga Amy Fitzgerald, responsable de la obra colectiva The Animals Reader : The Essential Classic and Contemporary Writings (Oxford, Berg Publishers, 2007), amén de correr a su cargo la coordinación de A Cultural History of Animals. El interés por los Animal Studies en el mundo anglosajón también se plasma en la fundación de revistas específicamente dedicadas al tema, destacando, sin lugar a dudas, Anthrozöos: A Multidisciplinary Journal of The Interactions of People \& Animals (publicada por Berg Publishers desde 1987, es el órgano oficial de la Internacional Society for Antrhozöology, fundada en 1991) y Society \& animals. Journal for human-animal studies (editada desde 1993 por Brill Academia Publishers), siendo su equivalente en el mundo académico galo Anthropozoologica, que desde 1984 publica el CNRS.

Con todas sus lagunas e insuficiencias (fundamentalmente, la preferencia por las épocas más recientes, y el predominio de los análisis sociológicos, antropológicos o etnológicos, antes que específicamente históricos), los Animal Studies parecen haberse anclado firmemente en el mundo académico anglosajón, por encima de modas pasajeras o intereses académicos coyunturales. Muy distinto es, por el contrario, el panorama en el ámbito historiográfico español, y, más específicamente, por ser el que mejor conocemos, en el modernista, por cuanto estas cuestiones poco han interesado a los especialistas en Historia Moderna ${ }^{10}$, salvando, muy recientemente, la notable excepción de Carlos Gómez-Centurión ${ }^{11}$. Las principales contribuciones,

${ }^{8}$ POTTS, Annie, "Kiwis Against Possums: A Critical Analysis of Anti-Possum Rhetoric in Aotearoa New Zealand", Society \& Animals, 2009; POTTS, Annie, y WHITE, M., "New Zealand Vegetarians: At Odds with their Nation", Society \& Animals 16-4, 2008, pp. 336-353.

${ }_{9}$ ARMSTRONG, Philippe, What Animals Mean in the Fiction of Modernity. Londres y Nueva York, Routledge, 2008.

${ }^{10}$ Por ejemplo, de un animal tan ibérico y tan emblemático como el lobo, solamente se recogen en Dialnet (muy representativo de lo que se publica en el ámbito académico español) dos aportaciones relativas a su persecución en la época moderna: SOBRADO CORREA, H., "Los enemigos del campesino. La lucha contra el lobo y otras alimañas nocivas", Obradoiro de historia moderna, 12, 2003; TRISTAN GARCIA, F., "Va el lobo. Aproximación histórica en la tierra de Baza en la alta edad moderna", Chronica Nova, 27, 2000.

${ }^{11}$ GOMEZ CENTURION, Carlos, "Exóticos pero útiles: los camellos reales de Aranjuez durante el siglo XVIII”, Cuadernos dieciochistas, 9, 2008, pp. 155-180; “Treasures fit for a king. King Charles 
de hecho, no proceden del terreno específicamente histórico, sino de disciplinas que podríamos llamar colaterales, bastante ignoradas normalmente dado que en nuestro país los compartimentos estancos existentes entre las distintas ramas humanísticas suelen estar bastante infranqueados.

Y esta laguna no puede ser atribuible, en modo alguno, a falta de información. Tan sólo para lo que se refiere a la época moderna, podríamos contar al respecto con la literatura emblemática ${ }^{12}$ y simbólica, la producción cinegética y ecuestre ${ }^{13}$, y la literatura zoológica ${ }^{14}$, sin olvidar las aportaciones de la literatura fabulística (Steinhowell, Fábulas de Esopo, y, por supuesto, Iriarte y Samaniego), médica (por poner un ejemplo, el Dioscórides de Andrés Laguna), hagiográfica (los Flos Sanctorum de Villegas y Ribadeneyra), demonológica (Jardín de Flores curiosas de Torquemada, Patrocinio de ángeles y combate de demonios de Blasco Lanuza,

III of Spain's Indian Elephants", Journal of the History of Collections, 2009, pp. 29-44; "Exóticos y feroces. La ménagerie real del Buen Retiro durante el siglo XVIII", Goya. Revista de Arte, 326, 2009, pp. 3-25; "Curiosidades vivas. Los animales de América en la Ménagerie real durante el siglo XVIII", Anuario de Estudios Americanos, 66, 2, 2009, pp. 181-211.

${ }^{12}$ Hay muchos títulos de interés, que podemos encontrar en la Ornitología emblemática de García Arranz. Nos conformaremos con citar FERRER DE VALDECEBRO, Andrés, Gobierno general, moral y politico, halado en las fieras y animales silvestres (Madrid,1658), y Gobierno general, moral y político, hallado en las aves... añadido con las aves monstruosas (Madrid, 1683), GARAU, Francisco, El sabio instruido de la naturaleza en cuarenta máximas políticas y morales (Barcelona, 1702), MARCUELLO, Francisco, Primera parte de la historia natural y moral de las aves (Madrid, 1617), o RAMÍREZ DE CARRION, Maravillas de naturaleza (Córdoba, 1629).

${ }^{13}$ ANONIMO, Diálogo de la montería, ARGOTE DE MOLINA, Libro de la montería, BARAHONA DE SOTO, Diálogos de la montería, BUFANDA, Compendio de las leyes expedidas sobre la caza, CALVO PINTO, Silva venatoria, FERNÁNDEZ DE ANDRADA, Libro de la gineta de España, MANZANAS, Libro de enfrentamiento de la jineta, MARTINEZ DE ESPINAR, Arte de ballestería y montería, MATEOS, Origen y dignidad de la caza, NÚÑ̃Z DE AVENDAÑO, Aviso de cazadores $y$ de caza, TAMARIZ DE LA ESCALERA, Tratado de la caza del vuelo, TAPIA SALCEDO, Exercicios de la gineta, ZUÑIGA, Libro de cetrería de caza de azor.

${ }^{14}$ Prescindiendo de la literatura generada por el descubrimiento del continente americano, que se puede consultar en la obra de ASUA, Miguel de, y FRENCH, Roger, A new world on animals. Early modern europeans on the creatures of Iberian America (Aldershot, 2005), podemos citar para los siglos XVI y XVII, CORTES, Libro y tratado de los animales terrestres y volátiles (1613), o VELEZ DE ARCINIEGA, Libro de los cuadrúpedos y serpientes terrestres, recibidos en el uso de la medicina (1597), Historia de los animales más recibidos en el uso de la medicina (1613). De la producción dieciochesca, cabría destacar: ASSO, "Introducción a la ictiología", Anales de Historia Natural, tomo 10. AZARA, Apuntamientos para la historia natural de los cuadrúpedos del Paraguay y del Río de la Plata (Madrid, 1802), y Apuntamientos para la historia natural de los pájaros del Paraguay y del Río de la Plata (Madrid, 1802-1805). BRU, Colección de láminas que representan los animales y monstruos del Real Gabinete de Historia Natural (Madrid, 1784). CAVANILLES, "Historia natural de las palomas domésticas de España especialmente de Valencia", Anales de Historia Natural, 2, 1799. CORNIDE, Ensayo de una historia de los peces y otras producciones marinas de la costa de Galicia (Madrid, 1788). Descripción del elefante, de su alimento, costumbres, enemigos e instintos (Madrid, Imprenta de Andrés Ramírez, 1773). GARRIGA, Descripción del esqueleto de un quadrúpedo muy corpulento y raro que se conserva en el Real Gabinete de Historia Natural de Madrid (Madrid, Joaquín Ibarra, 1796). PARRA, Descripción de diferentes piezas de historia natural las más del ramo marítimo (La Habana, 1787). 
Tribunal de superstición ladina de Gaspar Navarro), la prensa (Semanario de Agricultura y Artes), la propia literatura de creación (las novelas de caballerías, por ejemplo, y algunos títulos tan singulares como la Gatomaquia de Lope de Vega), la inmensa producción generada por la exploración del continente americano, o los diccionarios (Tesoro de la lengua castellana de Covarrubias y Diccionario de la Real Academia española)...y solamente nos referimos a las fuentes de carácter libresco, ya que la iconografía y la documentación de carácter artístico nos brindan un material impresionante que poco ha sido utilizado en estos menesteres.

\section{Tres visiones del mundo animal}

Las etapas históricas al uso no tienen razón de ser en la historia cultural de los animales, sucediéndose a lo largo del tiempo una serie de visiones hegemónicas, pero nunca exclusivas, ya que jamás llegan a desplazar por completo a la anterior, con la que coexiste sin que ello suponga una contradicción. En este sentido, habría que distinguir una primera fase, que llegaría hasta mediados del Seiscientos, en la cual predomina la visión simbólica, según la cual los animales tienden a ser considerados, en última instancia, como un mero espejo de los vicios y virtudes humanos. La segunda visión, la positivista, estaría marcada fundamentalmente por los intereses descriptivistas, siguiendo las pautas establecidas por lo que se ha dado en llamar el método científico que se consolida a partir del siglo XVII . Y la tercera, la afectiva (muy relacionada con su antítesis, la visión utilitaria, que siempre ha estado presente), que no empieza a dar frutos hasta el siglo XIX con las primeras medidas proteccionistas (aunque con antecedentes muy antiguos, siendo Plutarco el ejemplo más destacado), y que se caracterizaría por el intento de establecer un marco de relación más igualitario entre los animales y los seres humanos, a la par que se consolida su papel como iconos del universo infantil. Todas estas visiones las vamos a encontrar a lo largo de la Modernidad ${ }^{15}$.

Los orígenes de la visión simbólica se remontan a la época clásica, siendo Plinio el autor que, posiblemente, tuvo mayor impacto, continuado por Claudio Eliano, Solino, y el epílogo que supondría la figura de Isidoro de Sevilla. Durante este período confluirían la moralización del mundo animal, en el que cada especie se podría asimilar a una virtud o un vicio humano (fruto de la tradición fabulística iniciada por Esopo), y el recurso a lo mágico, lo mítico, lo maravilloso y lo fantástico, en el que la India supone la tierra de maravillas por excelencia (que ya apreciamos en la obra de Heródoto) ${ }^{16}$. La Edad Media heredaría ambas tendencias ${ }^{17}$, inspirándose sobre todo en la obra del Fisiólogo,

\footnotetext{
${ }^{15}$ Una buena panorámica de las distintas vertientes del estudio de los animales durante esta época, en ENENKEL, K.A.E., y SMITH, P.J., Early modern zoology: the construction of animals in science, literature and the visual arts, Leiden, Brill, 2007.

${ }^{16}$ WITTKOWER, Rudolf, "Maravillas de Oriente: Estudio sobre la historia de los monstruos", Sobre la arquitectura en la edad del Humanismo. Ensayos y escritos. Barcelona, Editorial Gustavo Gili, 1979, pp. 265-311.

${ }^{17}$ FUENTE FREYRE, J. A. de, La biología en la Antiguedad y en la Edad Media, Salamanca, Universidad, 2002.
} 
supuestamente atribuido a san Epifanio (cuya traducción del griego fuera publicada en la Roma de 1587 por Gonzalo Ponce de León), copiada, ampliada, adulterada y plagiada hasta la saciedad, y que daría origen a los tan conocidos bestiarios, en los que predominaría igualmente la visión simbólica. Escasas figuras realizarían durante este período una aportación original, pudiendo destacarse, especialmente, la obra de San Alberto Magno, De animalibus. El siglo XVI no supondría en absoluto una ruptura con la cosmovisión zoológica heredada del pasado, ya que lo maravilloso y lo mítico, muy revitalizados por la publicación de la obra de Olao $\mathrm{Magno}^{18}$, que trasladará el reino de las maravillas de la India a los mares del Septentrión, seguirán teniendo cabida en la abundante literatura teratológica publicada durante este período, a la par que la vertiente simbólica se vería reforzada por la difusión de la literatura emblemática.

La visión simbólica del mundo animal ha sido bastante estudiada en lo que se refiere a la España moderna, y los historiadores del arte son, probablemente, los que nos han ofrecido mayor número de aportaciones a través del tratamiento de la literatura emblemática ${ }^{19}$, en cuyo análisis tendríamos que destacar a José Julio García Arranz, especialmente la obra que en su momento constituyó su tesis doctoral Ornitología emblemática (Universidad de Extremadura, 1996), acompañada de numerosos trabajos posteriores $^{20}$. Esta visión simbólica es la que han abordado también, normalmente, los historiadores de la literatura, a los que debemos algunas aportaciones relativas a la fauna, real o fantástica, descrita en la literatura religiosa ${ }^{21}$, o alguna referencia a la obra fabulística de Samaniego ${ }^{22}$.

${ }^{18}$ MAGNO, Olao, Historia de las gentes septentrionales, Madrid, Tecnos, 1989, edición de Daniel Terán Fierro, que utiliza el epítome latino publicado en Amberes en 1562, aunque la edición princeps es la de Roma de 1555.

${ }^{19}$ PICINELLO, Francisco, El mundo simbólico. Serpientes y animales venenosos. Los insectos, México, El Colegio de Michoacán, 1999, a destacar los estudios introductorios, ROIG CONDOMINA, V.M., "Los emblemas animalísticos de fray Andrés Ferrer de Valdecebro", Goya, 187-188, 1985, o SOLERA LOPEZ, R., "Estudio iconográfico del jabalí como animal simbólico y emblemático", Emblemata: Revista aragonesa de emblemática, 7 (2001).

20 "La literatura animalística ilustrada en España durante la Edad Moderna: una panorámica, $L i$ bros con arte, arte con libros, 2007; "Olao Magno y la difusión de noticias sobre fauna exótica del norte de Europa en el siglo XVI", Encuentro de civilizaciones (1500-1750) : informar, narrar, celebrar : actas del tercer Coloquio Internacional sobre relaciones de sucesos, Cagliari, 5-8 de septiembre de 2001, 2003; "Las enciclopedias animalísticas de los siglos XVI y XVII y los emblemas: un ejemplo de simbiosis", Del libro de emblemas a la ciudad simbólica, 2000; "La visión de la Naturaleza en los emblemistas españoles del siglo XVII", Literatura emblemática hispánica : actas del I Simposio Internacional, 1996; "Fauna americana en los emblemas europeos de los siglos XVI y XVII", Cuadernos de arte e iconografía, 11 (1993); "El papagayo y la serpiente: historia natural de una empresa de Diego Saavedra Fajardo", Norba. Arte, 26, 2006.

${ }^{21}$ CUEVAS GARCIA, C.1, "El bestiario simbólico en el Cántico Espiritual de san Juan de la Cruz", Simposio sobre san Juan de la Cruz (1986). GOMEZ MORENO, A., Claves hagiográficas de la literatura española (del Cantar de mio Cid a Cervantes), Iberoamericana/Vervuet, 2008. HERNANDEZ MERCEDES, M.P., "El bestiario alegórico en el Dilucidario del verdadero espíritu de Jerónimo Gracián de la Madre de Dios", Estado actual de los estudios sobre el Siglo de Oro, vol. 1, Salamanca, Universidad, 1993, pp. 473-479.

22 PALACIOS FERNANDEZ, E., “Las fábulas de Félix María de Samaniego: fabulario, bestiario, fisiognomía y lección moral, Revista de literatura, 119, 1998. 
Muy distintos son los intereses de la visión positivista, que se centra en la descripción de las costumbres y comportamientos de las diferentes especies animales, así como de sus rasgos morfológicos y anatómicos. La primera vertiente ya la encontramos desde la más remota antigüedad, aunque mezclada con numerosos elementos fabulosos y legendarios. La segunda, si bien iniciada con Aristóteles, no se impondrá hasta la Revolución científica ${ }^{23}$, siendo un ejemplo fehaciente de ello la labor de la Academie des Sciences, fundada por Luis XIV en 1666, que se reflejaría en la publicación de Mémoires pour servir a l'histoire naturelle des animaux (1688), un esfuerzo colectivo dirigido por Claude Perrault (hermano del autor de los Cuentos de mamá Oca), donde se describían cerca de cincuenta especies, concentrándose básicamente en los aspectos anatómicos y prestando poca atención al comportamiento de los animales ${ }^{24}$.

Esta visión también ha sido abordada en el caso español, fundamentalmente por los historiadores de la ciencia, comenzando, por supuesto, con la literatura relativa a las nuevas perspectivas que abrió a la zoología el descubrimiento de la fauna americana, tras las primeras visiones que se limitaban a trasponer los viejos bestiarios medievales ${ }^{25}$ (y, de hecho, durante mucho tiempo lo mítico y lo fabuloso siguieron teniendo cabida ${ }^{26}$, destacando al respecto las referencias de López Piñero ${ }^{27}$, y, sobre todo, la obra pionera de Raquel Alvarez Peláez ${ }^{28}$, miembro del departamento de Historia de la Ciencia del CSIC, a la que podríamos añadir los trabajos de

${ }^{23}$ GUERRINI, Annita, Experimenting with human and animals : from Galen to animal rights, The John Hopkins University Press, 2003.

${ }^{24}$ ROBBINS, Louise E., Elephant slaves and pampered parrots: exotic animals in Eighteenth Century Paris, The John Hopkins University Press, 2002.

${ }^{25}$ FISCHER, M.L., "Zoológicos en libertad: la tradición del bestiario en el Nuevo Mundo", Revista Canadiense de Estudios Hispánicos, 20-3, 463-476, 1996; GOMEZ TABANERA, José Manuel, "Sobre el bestiario fantástico del Medioevo europeo y su gravitación al Nuevo mundo avistado por Colón (1492)", Congreso de Historia del Descubrimiento 1492-1556, vol. 1, pp. 459-498, "Bestiario y paraíso en los viajes colombinos; el legado del folklore medieval europeo a la historiografía americanista", Actas del XI Congreso de la Asociación Internacional de Hispanistas. Encuentros y desencuentros de culturas: desde la Edad Media al siglo XVIII, vol. 3, 1994.

${ }^{26}$ VOS, Pierre de, "The rare, the singular and the extraordinary: Natural History and the collection of Curiosities in Spanish Empire", BLEICHMAR, D., VOS, P.de, HUFFINE, K., y SHEEHAN, K., Science in the Spanish and Portuguese Empires 1500-1800, Stanford U.P., 2007. Algunas aportaciones de interés en STOLS, E., THOMAS, W., y VERBERCKMOES, J., (eds.), Naturalia, Mirabilia et Monstrosa en los Imperios ibéricos. Leuven University Press, 2006.

${ }^{27}$ LOPEZ PIÑERO, J.M., Ciencia y técnica; Medicina e historia natural en la sociedad española de los siglos XVI y XVII, Universitat de Valencia, 2007.

${ }^{28}$ La historia natural en los siglos XVI y XVII (Madrid, Akal, 1991) y La conquista de la naturaleza americana (Madrid, CSIC, 1993), "La historia natural en los tiempos del emperador Carlos V: la importancia de la conquista del Nuevo Mundo", Revista de Indias, 60, 218, 2000; "La descripción de las aves en la obra del madrileño Gonzalo Fernández de Oviedo", Asclepio, 48, 1, 1996; "La historia natural de los animales", GARCIA BALLESTER, Luis, Historia de la ciencia y de la técnica en la corona de Castilla, vol. 3 (siglos XVI y XVII), Valladolid, 2002. 
José Pardo Tomás ${ }^{29}$, Antonio Barrera ${ }^{30}$, los análisis sobre Francisco Hernández debidos a Simon Varey ${ }^{31}$, y, más recientemente, la magnífica visión de conjunto de Miguel de Asúa y Roger French ${ }^{32}$. La revista Asclepio, que representa lo mejor del panorama académico español en lo que se refiere a la historia de la ciencia, presenta asimismo algunas contribuciones interesantes ${ }^{33}$, centradas fundamentalmente en la política zoológica de los Borbones, siendo su máxima expresión la fundación del Real Gabinete de Historia Natural ${ }^{34}$, cuya prueba de fuego sería el análisis de los fósiles del megaterio, magistralmente descrito por Juan Pimentel Igea ${ }^{35}$. Estudiar animales implica además plasmarlos visualmente, no pudiéndose olvidar la obra del historiador del arte Barbero Richart, Iconografía animal. La representación animal en libros europeos de Historia Natural de los siglos XVI y XVII (Universidad de Castilla la Mancha, 1999), que aborda el fascinante mundo de las representaciones iconográficas incluidas en la rica literatura zoológica de la Modernidad.

Por lo que se refiere a la visión afectiva ${ }^{36}$, cuyo triunfo es más propio de la contemporaneidad, hay que partir de la base que desde la Antigüedad la consideración que han merecido los animales ha suscitado opiniones muy distintas, destacando al respecto, en el plano positivo, las valoraciones de Plutarco, y la escolástica medieval continuó con esta divergencia de opiniones. Por un lado, hay quienes los oponen al hombre, como criaturas sumisas e imperfectas que son, y esta corriente insiste en su dominio absoluto sobre los animales (lo que llamamos visión utilitaria): tal como bien subrayan Karl Enenkel y Paul Smith, la única razón de éstos es la de servir

${ }^{29}$ PARDO TOMAS, José, "La expedición de Francisco Hernández a México”, Felipe II, la ciencia y la técnica, Madrid, 1999; El tesoro natural de América: colonialismo y ciencia en el siglo XVI. Oviedo, Monardes, Hernández, Madrid, Nivola, 2002; Un lugar para la ciencia: escenarios de práctica cientifica en la sociedad hispana del siglo XVI, Fundación Canaria Orotava, 2006.

${ }^{30}$ BARRERA-OSORIO, A. Experiencing Nature. The Spanish American Empire and the Early Scientific Revolution, Texas U.P., 2006; "Knowledge and Empiricism in the Sixteenth Century Spanish Atlantic World", Science in the Spanish.

${ }^{31}$ VAREY, S., (ed.), The mexican treasury: the writings of Dr. Francisco Hernández, Stanford U.P., 2000; VAREY, S., CHABRAN, R., y WEINER, D.W., (eds.), Searching for the secrets of nature. The life and works of Dr. Francisco Hernández. Stanford U.P., 2000.

${ }^{32}$ ASUA, Miguel de, y FRENCH, Roger, A new world of animals.

${ }^{33}$ Por citar tan sólo las más recientes, MAZO PEREZ, A.M., "El oso hormiguero de su Majestad" $(58,1,2006)$, ZARZOSO, M., "Medicina para animales en la Cataluña del siglo XVIII" $(59,1,2007)$, y MALDONADO POLO, L., "Las expediciones científicas españolas en los siglos XIX y XX en el archivo del Museo Nacional de Ciencias Naturales" (53, 1, 2001).

${ }^{34}$ CALATAYUD ALONSO, M.A., "El Real Gabinete de Historia Natural de Madrid", SELLES, M., (comp.), Carlos III y la ciencia de la Ilustración, Madrid, Alianza, 1988. PIMENTEL IGEA, Juan "La naturaleza representada. El Gabinete de Maravillas de Franco Dávila", Testigos del mundo. Ciencia, literatura y viajes en la Ilustración, Madrid, Marcial Pons, 2003. VILLENA, M., et al., El gabinete perdido. Pedro Franco Dávila y la Historia Natural del siglo de las Luces, 2 vols., Madrid, CSIC, 2008. Para un contexto general, BLEICHMAR, D., "A visible and useful empire: Visual Culture and Colonial Natural History in the Eighteenth Century Spanish World", Science in the Spanish.

${ }^{35}$ PIMENTEL IGEA, Juan, El rinoceronte y el megaterio, Madrid, Abada, 2010.

${ }^{36}$ WOLLOCH, N., Subjugated animals. Animals and Anhtopocentrism in Early Modern European Culture, Nueva York, 2006. También FUDGE, E., Brutal Reasoning. FUDGE, E., WISEMAN, S., y GILBERT, R., At the Borders of the Human, THOMAS, K., Man and the Natural World. Change attitudes in England 1500-1800, Londres, Penguin Books, 1983. 
al ser humano, proporcionándole comida, ropa, medios de transporte, medicinas, $\mathrm{y}$ entretenimiento ${ }^{37}$. Pero hay otra corriente que pretende ver un vínculo y un parentesco biológico y trascendente entre el hombre y los animales, encontrándose la justificación bíblica en Rom. 8, 21, donde podemos leer "la creación entera espera anhelante ser liberada de la servidumbre de la corrupción, para participar en la libertad de la gloria de los hijos de Dios". Ello hizo que muchos se preguntaran si Jesús vino a salvar también a los animales, y la escolástica se planteaba si iban al cielo, si podían trabajar los domingos o si tenían responsabilidad moral, lo que llevó, en un caso extremo, a los juicios contra animales, muy frecuentes en los últimos siglos medievales en Francia, siendo los cerdos las víctimas propiciatorias más frecuentes ${ }^{38}$, en tanto que en España los procesos contra la langosta fueron moneda de cambio muy habitual a lo largo de los siglos XVI y XVII ${ }^{39}$.

Poco ha sido tratada esta vertiente en el caso español. Contamos con alguna aportación relativa a los debates intelectuales dieciochescos en los que había que tomar postura ante el rígido mecanicismo cartesiano: el mismo Feijoo se ocuparía de ello en su "Discurso sobre el alma de los brutos" (Teatro crítico universal, tomo III, discurso IX, 1729), criticado por Miguel Pereira de Castro en su Propugnación de la racionalidad de los brutos (Lisboa, 1753) ${ }^{40}$. También tenemos aportaciones sobre lo que podríamos considerar la antítesis de esta visión, por cuanto supone la manifestación más extrema de señorío del hombre sobre los animales, a saber, la caza ${ }^{41}$. Pero poco sabemos acerca de la presencia de los animales domésticos o las mascotas en el mundo hispánico ${ }^{42}$, de la consideración que merecían hacia sus dueños, o de las especies más recurrentes, aunque contemos con algunas fuentes que permiten abordar esta cuestión, tales las obras de Pedro Fernández de Andrada, De la naturaleza del caballo (1580), Luis Pérez, Del can, del caballo y de sus cualidades (1568), o Juan Bautista Zamarro, Conocimiento de las catorce aves menores de jaula (Madrid, 1775).

${ }^{37}$ ENENKEL, K.A., y SMITH, P.J., "Introduction”, Early Moderrn Zoology, p. 2.

${ }^{38}$ PASTOUREAU, Michel, Una historia simbólica, pp. 27-30.

39 SANZ DAROCA, C., Las respuestas religiosas ante las plagas del campo en la España del siglo XVII, Madrid, UNED, 2008, Tesis doctoral inédita.

${ }^{40}$ RODRÍGUEZ PARDO, José Manuel, El alma de los brutos en el entorno del padre Feijoo, Oviedo, Pentalfa Ediciones, 2008.

${ }^{41}$ FRADEJAS RUEDA, J.M., Textos clásicos de cetrería, montería y caza, Madrid, Mapfre, 1999; TERRON, M., El conocimiento animalístico de la caza mayor en los clásicos de la montería hispana, Trujillo, 1992. El contexto ideológico, en CARO LOPEZ, J., "La caza en el siglo XVIII: sociedad de clase, mentalidad reglamentista", Hispania, 224, 2006.

${ }^{42}$ A la espera de la obra de Carlos Gómez Centurión sobre estos aspectos, solamente podemos citar a PEREZ DE TUDELA, A., y JORDAN, A., "Renaissance Menageries, Exotic Animals and Pets at the Habsburg Courts in Iberia and Central Europe", ENENKEL, K.A.E., y SMITH, P.J., Early Modern Zoology. 


\section{Un modelo de visión simbólica: la obra de Covarrubias}

Un buen ejemplo de la concepción simbólica del mundo animal en la España moderna viene dado por la figura de Sebastián de Covarrubias y su Tesoro de la lengua castellana o española, que viera su primera edición allá por 1611. Su obra puede ser considerada un buen exponente de la cosmovisión que un hombre culto y letrado, dotado de una educación libresca en la cual el componente clásico seguía teniendo una importancia fundamental, y en la que la referencia a la autoridad era todavía inexcusable ${ }^{43}$, podía tener en la España de inicios del siglo XVII. Y, más particularmente, del mundo animal, que será el objeto de este trabajo, siendo partícipe, básicamente, de una visión simbólica plenamente operativa.

El elenco de especies animales incluidas es bastante considerable, aunque muy inferior a las conocidas por aquel entonces: Covarrubias recoge un total de 79 mamíferos $^{44}$ (si bien la cifra real sería inferior, ya que incluye las distintas denominaciones que se pueden dar de una misma especie, cual es el caso del perro o el caballo), omitiendo algunos tan conocidos hoy día para todos como pudieran ser el tigre o el leopardo, 63 aves ${ }^{45}, 15$ reptiles y anfibios ${ }^{46}, 34$ peces $^{47}, 41$ invertebrados ${ }^{48}, \mathrm{y}$ 15 animales fantásticos ${ }^{49}$, extraídos sobre todo de la mitología grecolatina. El espacio dedicado a cada uno de ellos varía considerablemente, oscilando desde un par de líneas (como el sargo, del que se limita a decir que es pescado de mar), a las más de 7000 palabras dedicadas al elefante, sin lugar a dudas, y con gran diferencia,

${ }^{43}$ LEWIS, C.S., La imagen del mundo. Introducción a la literatura medieval y renacentista. Barcelona, Península, 1997, pp. 13-14, 18.

${ }^{44}$ Acémila, alce, armiño, asno, bada (rinoceronte), ballena, becerro, bisonte, buey, búfalo, burra, caballo, cabra, camello, castor, cebra, ciervo, cochino, comadreja, conejo, delfín, dromedario, elefante, erizo, espín puerco, foca, fuina, galgo, gamuza, garañón, garduña, gato, gazapo, gineta, haca, harda (ardilla), hiena, hipopótamo, hurón, jabalí, jumento, lebrel, león, liebre, lince, lirón, lobo, marta, mastín, mono, morueco, mulo, murciélago, murgaño, novillo, nutria, orca, oso, oveja, perro, podenco, pollino, potro, puerco, raposa, ratón, rinoceronte, rocín, tejón, ternero, toa, topo, toro, turón, vaca, varraco, venado, vulpeja, zurra (zorra).

${ }^{45}$ Abejoruco, abubilla, águila, alcaraván, alcaudón, alcotán, alfaneque, alondra, ánade, ánsar, autillo, avestruz, avión, avutarda, azor, baharí, buitre, búho, calamón, cerceta, cernícalo, chucho, cigüeña, cisne, clueca, codorniz, corneja, cuclillo, cuervo, estornino, faisán, falcón, flamenco, francolín, gallina, gallo, ganso, garza, gavilán, gaviota, girifalte, golondrina, gorrión, grajo, grulla, halcón, hurraca (sic), ibis, lechuza, mirla, mochuelo, paloma, papagayo, pavo, perdiz, pito, pollo, ruiseñor, sacre, tordo, tórtola, vencejo, zorzal.

${ }^{46}$ Aspide, caimán, camaleón, cocodrilo, culebra, estelión, galápago, lagarto, rana, renacuajo, salamandra, sapo, serpiente, tortuga, víbora.

${ }^{47}$ Abadejo, acedia, aleche, anchova, anguilla, arenque, atún, barbo, bermejuela, besugo, carpa, cazón, céfalo, congrio, dorada, gobio, lamprea, lampuga, lenguado, lija, merluza, mero, murena, rodaballo, sábalo, saboga, salmón, salpa, sardina, sargo, sollo, tiburón, toñina, trucha.

${ }^{48}$ Abeja, alacrán, almeja, araña, avispa, calamar, camarón, cangrejo, caracol, centolla, chinche, cientopiés, cigarra, cucaracha, escarabajo, escolopendra, escorpión, esponja, gámbaro, garrapata, gorgojo, grillo, gusano, hormiga, jibia, langosta, langostín, lombriz, luciérnaga, mosca, moscarda, mosquito, oruga, piojo, polilla, pulga, pulpo, sabandija, tábano, tarántula, zángano.

${ }^{49}$ Basilisco, cancerbero, catoblepas, cerbero, cinocéfalo, dragón, esfinge, fénix, grifo, harpía, hidra, lamia, pegaso, quimera, unicornio. 
la especie tratada con mayor prolijidad, a lo que no debió ser ajena la preferencia manifestada por Plinio en su Historia natural hacia esta especie, por delante incluso del león ${ }^{50}$, considerándolo nuestro autor

«el mayor de todos los animales y en los sentidos parece ir a los alcances al hombre... vienen a percebir la lengua de los que los crían, que hablan con ellos, y hacen lo que les mandan, y aprenden cuanto les enseñan, y tienen dello memoria; son amigos de que les regalen, los muestren amor y los alaben y honren; y se halla en ellos una manera de bondad, prudencia y equidad (p. 748)» ${ }^{51}$

Aunque no hay que perder de vista que, a medida que avanzamos en el abecedario, el espacio dedicado a las distintas voces zoológicas tiende a ser más reducido, quizás por la premura del autor en finalizar su magna obra.

Las especies descritas pertenecen en su inmensa mayoría al Viejo Mundo, y llama la atención el silencio que Covarrubias manifiesta con respecto a la fauna americana (de hecho, hasta la publicación en 1635 de la obra de Nieremberg Historia naturae maxime peregrinae, la fauna del Nuevo Mundo no se integraría definitivamente en la animalística de la modernidad) $)^{52}$ : es cierto que nos habla del caimán, el papagayo, "ave índica conocida" (p. 1342), o el pavo, "gallo de las Indias" (p. 1350), pero no incluye, por ejemplo, el armadillo, que sí aparece ya en la obra de Gessner, lo que podría deberse al hecho de que el conocimiento de estos nuevos animales no trascendió de círculos muy reducidos (por lo que sus denominaciones no se incorporaron al vocabulario cotidiano) y no a ignorancia por parte del autor, ya que algunos de los libros que trataban las nuevas especies descubiertas y que circulaban por la España del momento son utilizados por Covarrubias en alguna ocasión: en la voz "América", cita a Gonzalo Fernández de Oviedo, Francisco López de Gómara y José de Acosta (p. 153), en "elefante", a Acosta (p. 753), en "tiburón", a Gómara (p. 1469).

Por lo que se refiere a las fuentes empleadas, son las propias de la cultura erudita y libresca de inicios del siglo XVII. Es muy habitual el recurso a la Biblia, así como a autores grecolatinos, de los que destacan, por encima de todo, Plinio e Isidoro de Sevilla, aunque también encontramos referencias a Aristóteles, Cicerón, Eliano, Filóstrato, Horacio, Lucano, Marcial, Ovidio, Pausanias, Persio, Plutarco, Procopio, Solino, Varrón, y Virgilio. Los tratadistas medievales son sistemáticamente ignorados, a excepción del Fisiólogo, del que recoge el típico elemento legendario ${ }^{53}$, y Alberto

${ }^{50}$ PASTOUREAU, Michel, El oso, p. 162.

${ }^{51}$ COVARRUBIAS HOROZCO, Sebastián de, Tesoro de la lengua castellana o española, edición de Ignacio Arellano y Rafael Zafra. Universidad de Navarra/Editorial Iberoamericana, 2006, p. 172. Para no multiplicar las notas innecesariamente citamos la página en el texto, siempre tomando como referencia esta edición.

${ }^{52}$ PIMENTEL IGEA, Juan, "E. Nieremberg, American Wonders and Preterimperial Natural History", Science in the Spanish...

53 "Hablando de la naturaleza del elefante, que la hembra busca la hierba que se llama mandrágora, y después que la ha gustado, instigada de un apetito lujurioso, busca al consorte y se la presenta; él la come, y se enciende en amoroso ardor, que le despierta a juntarse con la hembra" (p.757). 
Magno (citado en el término esfinge). Tampoco es muy amigo de consultar las grandes enciclopedias zoológicas del siglo XVI, si salvamos alguna mención aislada a las obras de Conrad Gessner (alce, tordo), Guillaume Rondelet (ballena, carpa, céfalo, orca, sábalo, salmón), o Ulises Aldrovandi (cetrería). Más habitual es en el recurso al Dioscórides (anchova, bada, caracol, cigarra, víbora), según la edición castellana que del mismo realizara Andrés Laguna; a arabistas como Diego de Urrea (acémila, alcotán, azor) y el padre Guadix (almeja, azor, baharí, caracol, garduña, garza, halcón); o a historiadores como Ambrosio de Morales (león), Diego Pérez de Mesa (langosta) o Juan de Mariana (cabra). Y, sobre todo, Covarrubias prefiere extraer información contemporánea de la literatura emblemática y simbólica, de la que se muestra como un buen conocedor ${ }^{54}$, muy en la línea de lo que le interesa poner de relieve de cada especie animal, a saber, la vertiente moralizante. Así, sin querer ser demasiado exhaustivos, figuran entre sus fuentes, entre otras, Andrea Alciato, y sus archiconocidos Emblemas (águila, alce, anguila, asno, cigarra, cigüeña, corneja, delfín, elefante, esfinge, gallo, murciélago, sardina, vibora); Angelo Poliziano (águila, bada, cisne), Giambattista Della Porta y su De humana physiognomonia libri III (halcón); Horapolo y sus Hyerogliphica (escarabajo); Juan de Horozco y sus Emblemas morales (víbora); Pierio Valeriano y sus Hieroglyphica sive de sacris Aegyptiorum litteris commentarii (águila, bada, buitre, caballo, camaleón, ciervo, esfinge, hipopótamo, langosta, lechuza, león), o Ricardo Brixiano y sus Comentaría Simbólica (cuervo, fénix, león).

La utilización de toda esta literatura es muy coherente con el hecho de que a Covarrubias lo que le interesa sobre todo es poner de relieve la vertiente simbólica: en algunas ocasiones nos describe todas las empresas, refranes, emblemas y jeroglíficos relacionados con cada animal en cuestión (siendo algunos de los más privilegiados al respecto la abeja, el asno, el buey, el ciervo, el elefante, el gallo, el león, y el águila, que en la literatura emblemática es, al menos entre las aves, el animal con mayor volumen de representaciones $)^{55}$, a la par que los relaciona con virtudes y vicios típicamente humanos, reconociendo su valor pedagógico y lo que el hombre puede aprender de ellos $^{56}$. Así, es frecuente que nuestro autor recoja refranes donde los animales aparecen claramente como protagonistas, o que encontremos relatos morales, como el de Torquemada y su asno, que le invita a reflexionar "de los que dondequiera que vayan llevan en su compañía un necio pesado" (p. 234). O puede utilizar a los diferentes animales para identificarlos con vicios y virtudes: la abeja destaca por su industria y su sagacidad, siendo símbolo de la castidad y de la elocuencia (p. 21). El camaleón, simboliza el hombre astuto, disimulado y sagaz (p. 413). De la cigüeña, destaca

\footnotetext{
${ }^{54}$ MORREALE, Margarita, "Los Emblemata de Alciato en el Tesoro de la Lengua castellana de Sebastián de Covarrubias", Nueva Revista de Filología Hispánica, XL-1, 1992, pp. 343-382.

${ }^{55}$ GARCIA ARRANZ, J., Ornitología emblemática.

${ }^{56}$ Hablando de la golondrina, nos señala cómo "muchas cosas parece habernos enseñado los animales brutos cuadrúpedes, reptiles, aves y peces, concernientes a nuestro gobierno y policía; y entre los demás, dicen que la golondrina nos enseñó el edificar casas y hacer muros de argamasa y reparos para las crecientes de los ríos, pues hace su nido tan fuerte y fornido, formando de tierra y del agua, que lleva en su pico, y pajuelas su casita" (p. 982).
} 
su gobierno, que parece humano y político, por cuanto en la parte donde se han de juntar para partirse, castigan a la que se tarda (p. 533).

Por lo que se refiere al elefante,

en él se halla cierta manera de religión, por cuanto cuando sale el sol acostumbra el elefante hacer ciertas muestras de reverenciarle y adorarle, purificándose con el agua lustral, y también adora la luna nueva, y busca las aguas vivas y corrientes en que lavarse. Si se halla enfermo, parece invocar al cielo (p. 756).

El gallo, es ave peleona y lujuriosa (p. 950). La golondrina, símbolo del huésped molesto (p. 981). El hipopótamo, de impiedad, irreverencia, ingratitud e injusticia (p. 1059). La tortuga, de la tardanza (p. 1482).

Sin olvidar, naturalmente, que dentro de esta concepción simbólica algunos animales presentan rasgos claramente demoníacos. Aquí, Covarrubias se remite normalmente a aquellos seres más denostados por las fuentes bíblicas, actualizadas en la España de los siglos XVI y XVII por la literatura devocional, tales la culebra, "en las sagradas letras se toma muchas veces por el demonio y por el Anticristo" (p. 652), el dragón, "sinificado el demonio en las Sagradas Letras y particularmente en muchos lugares del Apocalipsis", el escorpión, "sinifica al demonio, del cual se puede entender, no menos que del escorpión terrestre, ponzoñoso y engañoso" (p. 732), la serpiente, "tomó por instrumento el enemigo universal del género humano, y revestido en ella engañó a nuestra madre Eva" (p. 1438), o la zurra (zorra), "siempre que en la Escritura se hallare este nombre de vulpeja, sinifica en el sentido espiritual, o el demonio o el hombre malo y astuto, y particularmente el hereje" (p. 1561). La única excepción vendrá constituida por la cabra, por cuanto aquí la referencia no es directamente bíblica, sino procedente de la literatura demonológica ${ }^{57}$, y es por medio de la influencia de ésta por lo que Covarrubias la considera "símbolo del demonio, y en su figura cuentan aparecerse a las brujas y querer ser reverenciado dellas" (p. 387).

Escasas referencias encontraremos de la visión positivista. La taxonomía no es algo que a Covarrubias le interese demasiado, limitándose a definir las diferentes especies como cuadrúpedos, aves, reptiles, insectos (abeja), o animalejos (alacrán, harda o ardilla), participando en la inclusión, tan habitual en la época (la encontramos en Gessner y Rondelet), de todos los animales acuáticos entre los peces, puesto que la ballena es "el mayor pez de cuantos cría el mar" (p. 281), el caimán, "pez lagarto que se cría en las rías de Indias" (p. 394), el calamar, "pescado conocido" (p. 399), el pulpo, "pescado conocido" (p. 1382), lo que no hace más que seguir las tendencias clasificatorias de la época, basadas más en el hábitat que en caracteres anatómicos. Tampoco hace demasiado hincapié en las descripciones físicas y del comportamiento de las distintas especies. Estos elementos, ciertamente, se encuentran presentes en su obra, pero de un modo aislado y tangencial, y predominando, en gran medida, las

\footnotetext{
${ }^{57}$ PASTOUREAU, Michel, El oso, p. 244.
} 
noticias de carácter maravilloso y fantástico, que se mezclan indistintamente con los elementos reales ${ }^{58}$. Tampoco resulta muy explícito en sus ideas biológicas, si bien refleja la creencia, muy extendida por entonces ${ }^{59}$, de considerar que los ambientes húmedos, sucios y lóbregos permiten el nacimiento por generación espontánea de determinados animales: la polilla, "engéndrase de no sacudir y orear la ropa" ( $p$. 1369), la pulga, "se cría del polvo y de alguna humedad" (p. 1381), el ratón "suele engendrarse de la corrupción" (p. 1395).

Sí encontramos, por el contrario, numerosas referencias acerca de la valoración que le merece el mundo animal. Ante todo, la misma definición,

sustancia animada, adornada de sentido y movimiento, y entre todos el principal es el hombre por ser animal racional, y se dice del bruto, y es nombre genérico para él y para el hombre (p. 172).

Partamos de la base de que en la España de la época no había acuerdo acerca de la condición de los animales, oscilando las posturas existentes entre el automatismo de Gómez Pereira, precursor de la visión cartesiana al respecto, y plasmado en su Antoniana Margarita (Medina del Campo, 1554); hasta sus detractores, que les reconocían la capacidad de sentimiento, figurando entre ellos Francisco de Sosa en su «Endecálogo contra Antoniana Margarita, en el cual se tratan muchas y muy delicadas razones, y autoridades con que se prueba, que los brutos sienten y por sí se mueven» (Medina del Campo, 1556). Covarrubias parece estar más cercano a la segunda de las posturas, al reconocerles la capacidad de sentido, y al considerarlos no tan lejanos al género humano. De hecho, si consultamos el término "Bestia", nuestro autor nos lo definirá como "nombre genérico que comprehende todos los animales irracionales" (p. 322), con lo cual nos vuelve a indicar la idea de que el ser humano supone la perfección del reino animal, pero sin pertenecer en modo alguno a un universo distinto: la racionalidad es su gran diferencia (en lo que sigue, obviamente, los viejos planteamientos aristotélicos). A veces aparecen en las definiciones elementos claramente descalificatorios, dotando la imagen de

${ }^{58}$ Así, nos dice del águila que "mata el ciervo con maravillosa astucia...tiene particular enemiga con el dragón o sierpe" (p. 61). El buitre, "luego que le viene el tiempo de concebir (porque es hembra sin macho) está cinco continuos días sin comer, vuelta su natura al viento, del cual concibe, y está preñada dél ciento y veinte días, y en otros tantos saca sus pollos y los cría y los otros ciento y veinte queda libre y huelga, rehaciéndose y reforzándose. Para mayor confirmación desto dicen que pone trece huevos, los cuales responden a las trece conjunciones lunares que se hacen en el año solar" (p. 362). El camello, "sufre mucho la sed, caminando diez y doce dias sin beber, pero cuando halla el agua saca el vientre de mal año, y bebe por lo pasado y por lo porvenir" (p. 416). El cocodrilo, "es anfibio, que vive en el agua y en la tierra; tiene el cuero tan duro que no hay arma que le ofenda, si no es hiriéndole en la barriga, por donde el delfin, su natural enemigo, suele matarle, hiriéndole con las agudas púas que tiene en el espinazo y poniéndosele debajo" (p. 566).

${ }^{59} \mathrm{Y}$ que encontramos fielmente reflejada en el modo de generación de los trasgos descrito por FUENTELAPEÑA, Fray Antonio de, El Ente dilucidado. Discurso único novísimo que muestra hay en naturaleza animales irracionales invisibles y quales sean. Madrid, Imprenta Real, 1676. 
algunas especies de una carga de negatividad bastante acentuada, fundamentada casi siempre en su carácter dañino, sucio o feroz: la abubilla es "ave sucia" (p. 28), el bada (rinoceronte), "animal ferocísimo" (p. 271), el búho, "ave nocturna, infeliz y de mal agüero" (p. 367), el cochino "animal que solo nació para la cocina y la gula" (p. 564), el escorpión, "animalejo ponzoñoso" (p. 814), la loba y el lobo, "animales conocidos y perniciosos" (p. 1209), la raposa, "animal conocido y pernicioso" (p. 1394).

Covarrubias tiene una visión muy utilitaria del mundo animal, y hace mucho hincapié en los distintos servicios que pueden prestar al ser humano, desde el punto de vista de la alimentación, la vestimenta o el transporte; o de los diferentes prejuicios que pueden ocasionar, lo que no hace más que reflejar implícitamente la idea de que el hombre es el rey de la Creación, y todas las criaturas, por consiguiente, se encuentran a su servicio. Así, sus cualidades alimenticias, sobre todo en lo que se refiere a los peces y demás seres acuáticos, más valorados (aunque no siempre la valoración de Covarrubias corresponde a los gustos actuales) cuanto menor es su volumen de espinas, eterna preocupación de cualquier ictiófilo: el abadejo, también llamado bacalao, pescado que se trae seco para la gente común (p. 18); el aleche, del que se hace una salsa (p. 100); la almeja, comida de gente pobre (p. 131); la anchova, que se echa en las ensaladas (p. 163); el atún, cuyas ijadas son deliciosas (p. 248); el besugo, de carne delicada, sabrosa y libre de espinas (p. 323); la lamprea, pescado regalado y sin hueso ni espinas (p. 1163); el langostín (langostino), que se tiene por pescado regalado (p. 1166); el mero, bocado de príncipes (p. 1276); o el salmón, de excelente sabor y gusto (p. 1424). Valoraciones gastronómicas que no solamente se extienden a los peces, puesto que nos habla también de las delicias de la perdiz, sabrosa en su comer (p. 1355); el zorzal, que los antiguos tuvieron por comida regalada y golosa ( $\mathrm{p}$. 1559); o el caracol, más debatido por cuanto si Dioscórides alaba su sabor, Galeno lo considera de pesada digestión y no apto para gente delicada (p. 449).

Animales como fuente de alimento, pero también como fuente de vestir, teniendo el autor un especial cuidado en señalar qué especies son las más útiles por su piel, tales el armiño (p. 213), el avestruz (sus plumas, en este caso)(p. 254), el búfalo, muy común en Italia (p. 366), el castor (p. 474), la gamuza (p. 953) o el turón (p. 1497). Sin olvidar tampoco la utilidad que presentan los animales para el trabajo, y aquí la gran estrella, sin lugar a dudas, es el asno (el caballo, como es bien sabido, nunca tuvo mucha importancia en la economía agraria española, por ser un animal demasiado delicado y valorado como para destinarlo a tan ruines menesteres)(pp. 231-232), secundado eficazmente por los jumentos (p. 1146). O para la medicina, donde nos transmite creencias de origen ancestral: así, el cuerno del rinoceronte es un antídoto contra el veneno (p. 272), las chinches, bebidas con vino o con vinagre, contribuyen a expulsar las sanguijuelas pegadas a la garganta, en tanto que, introducidas por la uretra, remedian la retención urinaria (p. 520), las tripas de comadreja saladas y secadas al sol son un antídoto contra el veneno de las serpientes (p. 583)...

Sin perder de vista tampoco la utilidad que presentan los animales como elemento lúdico y recreativo, y aquí destacarían las referencias a las actividades cinegéticas: la caza es definida como "ejercicio de prender los animales y las aves", y en ella el lebrel actúa como eficaz ayudante, ya que "acometen las fieras y las embarazan de 
manera que puede el cazador llegar con seguridad a matarlas" (p. 1174). Vertiente lúdica que también conlleva la utilización del animal como elemento espectacular, y aquí destacaría, obviamente, la figura del toro, reconociendo cómo "los españoles son apasionados por el correr de los toros, y frisa mucho con los juegos teatrales de los romanos" (p. 1479). Covarrubias tampoco olvida que los animales exóticos pueden actuar como una fuente de prestigio para reyes y príncipes, que coleccionando estas fieras lejanas tienen la ocasión de mostrar a todos su universal poderío. Así, nos habla del rinoceronte de Manuel I de Portugal, y que éste enviara al papa León $\mathrm{X}^{60}$, o del que fuera propiedad de Felipe $\mathrm{II}^{61}$

que por mucho tiempo estuvo en Madrid; tenía aserrado el cuerno y estaba ciega, porque no hiciese daño, y curaban della con mucho recato por el peligro de los que la tenían a su cargo; de los cuales mató uno o dos (p. 272).

O de los elefantes que estuvieron en posesión de ambos personajes, destacando el filipino,

tan doméstico que metía la mano o trompa en las faltriqueras de los que le entraban a ver, y les sacaba los dineros o fruta que aposta traían en ellas (pp. 754-755).

Pero los animales también ocasionan perjuicios, y a Covarrubias le preocupan sobre todo aquellos seres que pueden provocar daños en las cosechas y en los ganados, y no tanto los transmisores de enfermedades, por cuanto durante esta época aún no había arraigado la idea de que eran los gérmenes presentes en determinados animales los propagadores de las mismas, expresada por primera vez por Girolamo Fracastoro en su De contagionibus et contagiosis morbis, libri tres $(1546)^{62}$. Así, la chinche,

da grande pesadumbre al hombre, porque en sintiendo en la cama su calor sale de sus escondrijos, y le muerde con tanto rigor que le hace despertar temblando; que sin duda debe tener algún tanto de ponzoña, y cuando tenga ventura de haberla a las manos, es tan hediondo el olor que echa de sí que no la osa matar y se contenta con arrojarla fuera de la cama (p. 520)

\footnotetext{
${ }^{60}$ Rinoceronte que fue inmortalizado por Alberto Durero (el cual, de paso, nunca lo vio), cuya ilustración fue copiada hasta la saciedad por todos los enciclopedistas zoológicos del momento, y que acabó sus días en el fondo del mar Tirreno en 1516. Vid. SALZGEBER, D., Alberto Durero: el rinoceronte. Santa Marta de Tormes, Lóguez Ediciones, 2005, y PIMENTEL IGEA, Juan, El rinoceronte y el megaterio...

${ }^{61}$ Es muy conocido el gusto de Felipe II por los elementos exóticos. Una descripción de su cámara de maravillas, en MORAN, J.M., y CHECA, F., El coleccionismo en España. De la cámara de las maravillas a la galería de pinturas. Madrid, 1985. Precisamente, el rinoceronte filipino fue el segundo ejemplar vivo que se conoció en la Europa del siglo XVI.

${ }^{62}$ Una visión rápida de las teorías médicas de la época, en LINDEMANN, Mary, Medicina y sociedad en la Europa Moderna. Madrid, Siglo XXI, 2001.
} 
La fuina, asesina de gallinas y palomas; el gorgojo, que se come todo el trigo (p. 935); el grillo, muy perjudicial para los campos (careciendo de cualquier rasgo entrañable, a diferencia de nuestros días, donde somos herederos de la visión disneyana al respecto)(p. 1002); la langosta, auténtica plaga en la España del Seiscientos,

según el daño que hace en los frutos de la tierra, y con tener unas alillas muy débiles suelen levantarse en el aire muchedumbre de langostas que cubren el sol y donde se asientan lo dejan todo roído y abrasado; en fin, plaga y azote de Dios por los pecados de los hombres (p. 1165);

La tarántula, araña ponzoñosa (p. 1460); o el topo, que mina las raíces (p. 1476).

Covarrubias, sin embargo, participa muy tímidamente de la visión afectiva, ya que de muy pocas especies animales nos muestra que sienta un cariño especial. $\mathrm{Si}$ los reyes absolutos en el mundo de las mascotas lo son en la actualidad el perro y el gato, no parece tener demasiada inclinación por este último, señalando su carácter de

animal doméstico, que limpia la casa de ratones... con ser tan casero jamás se domestica, porque no se deja llevar de un lugar a otro si no es metiéndole por engaño en un costal, y aunque le lleven a otro lugar se vuelve, sin entender cómo pudo saber el camino63 (p. 964).

Pero no es así con el perro,

símbolo de fidelidad y de reconocimiento a los mendrugos de pan que le echa su amo (pp. 1357-1358)

Valoración positiva que no es de extrañar, por cuanto en algunos ámbitos europeos, como la Inglaterra Tudor, conoció un gran desarrollo la literatura relacionada con la fidelidad canina ${ }^{64}$. Cariño que no aparece manifestado, empero, hacia otro animal muy valorado por la aristocracia inglesa ${ }^{65}$, a saber, el caballo, puesto que Covarrubias, asépticamente, se limita a afirmar que

en la lengua latina caballus significa lo que en la nuestra rocín o caballo viejo y cansado, cuales suelen ser los de los molineros y los demás de servicio, que no son para caballería de gente noble, ni para la guerra; de los cuales se derivó el nombre de caballero.

${ }^{63}$ Esta malquerencia hacia los gatos, considerados diabólicos, seguía presente en el siglo XVIII. Vid. DARNTON, Robert, "La rebelión de los obreros: la gran matanza de gatos en la calle Saint-Severin", La gran matanza de gatos y otros episodios de la historia cultural francesa. México, FCE, 1987.

${ }^{64}$ THOMAS, Keith, op. Cit., p. 108.

${ }^{65} \mathrm{Y}$ todavía a finales del siglo XIX los aristócratas ingleses valoraban más a sus caballos que a sus criados. Vid. TUCHMANN, Bárbara, La torre del orgullo 1890-1914: una semblanza del mundo antes de la Primera Guerra Mundial. Barcelona, Península, 2008. 


\section{Conclusión}

En definitiva, la obra de Covarrubias es un fiel exponente de la cosmovisión faunística existente en la España de inicios del Seiscientos, en la cual los autores clásicos seguían jugando un papel determinante, en la que seguían circulando historias fabulosas relativas a los distintos animales, resultado de unos parámetros culturales en los cuales la fidelidad a la autoridad tiene tanto peso como lo constatado empíricamente (para Covarrubias, y para muchos otros, tan auténtico era lo leído como lo visto) ${ }^{66}, \mathrm{y}$ en la que la vertiente moral y simbólica, heredada de la literatura emblemática, los bestiarios medievales, y el venerable Fisiólogo, seguía jugando un papel determinante, aunque este predominio de lo simbólico no impide ni mucho menos la aparición de elementos descriptivistas, utilitarios o afectivos, sin que ello suponga contradicción alguna. En otro ámbito distinto del conocimiento, podríamos señalar el caso de Newton, que supo compaginar sus intereses ocultistas con sus estudios astronómicos, sin considerar que ambas fuesen actividades incompatibles ${ }^{67}$. $\mathrm{O}$ el de los autores de literatura demonológica, comenzando por el gran Jean Bodin, que hablaron con la misma seriedad y el mismo rigor del demonio que de otros temas supuestamente más racionales, porque todo ello formaba parte de su visión del mundo ${ }^{68}$. Tal como ha puesto de relieve Peter Galison con su concepto de trading zones, individuos adscritos a distintos paradigmas pueden colaborar en una empresa común ${ }^{69}$, y esta convivencia se puede aplicar también a escala individual: la cosmovisión es única, es el historiador el que la parcela.

Aunque su visión sea muy representativa (podemos acudir, a título de comparación, a la lectura de las obras de Ferrer de Valdecebro), no es, en modo alguno, original. En primer lugar, las fuentes empleadas por Covarrubias son idénticas a las de otros autores españoles que abordan el mundo animal: mucho Plinio (al fin y al cabo, es muy entretenido), y pocos naturalistas del siglo XVI. Aunque no sea un libro de Historia natural, podríamos señalar el ejemplo de Francisco Blasco Lanuza, que en su Patrocinio de Angeles y combate de demonios de 1652, aborda determinados aspectos relativos al mundo animal, que utiliza a Plinio sobremanera. Y Alonso Martínez de Espinar, en su Arte de ballestería y montería (1644), cita a Plinio cuando habla de la cabra montés (cap. 19). Lo mismo hará Agustín Calvo Pinto en su Silva venatoria (1754), ya que su bibliografía zoológica se limita a Plinio y Galeno, con alguna mención al muy socorrido Olao Magno. Y en la Descripción del elefante de 1773, aunque se cita a Buffon, tampoco podía faltar el autor clásico.

${ }^{66}$ "Cuando se hace la historia de un animal, es inútil e imposible tratar de elegir entre el oficio del naturalista y el del compilador: es necesario recoger...todo lo que ha sido relatado por la naturaleza o por los hombres", FOUCAULT, Michel, Las palabras y las cosas. Una arqueología de las ciencias humanas, Buenos Aires, Siglo XXI, 1968, p.47.

${ }^{67}$ VICKERS, Brian, "Introducción”, en VICKERS, Brian (comp.), Mentalidades ocultas y científicas en el Renacimiento, Madrid, Alianza, 1990.

${ }^{68}$ CLARK, Stuart, Thinking with demons. The idea of Witchcraft in Early Modern Europe, Oxford UP, 1999.

${ }^{69}$ Concepto desarrollado en GALISON, Peter, Images and logic: a material culture of microphysics, Chicago U.P., 1997. 
También participa de otra tendencia muy generalizada en la época, a saber, la presentación de un bestiario básicamente europeo, y, por extensión, del Viejo Mundo, en el cual las especies americanas tienen poco relieve. Podemos fijarnos a título de comparación en la obra de Joachin Camerarius, Symbolorum et emblematum ex animalibus quadrupedibus (1595), que recoge un centenar de emblemas, y solamente en uno aparece el armadillo, con una referencia dudosa al tapir, frente a los seis del león y el ciervo, y los cinco del perro, el caballo, la cabra y el oso. Y Andrés Ferrer de Valdecebro, por su parte, en su Gobierno general moral y político hallado en las fieras y animales silvestres (1658) incluye el león, el elefante, el rinoceronte, el unicornio, el tigre, la onza, el leopardo, la hiena, el lobo, el lince, el oso, el jabalí, el ciervo, el toro, el camello, el caballo, el can y el cinocéfalo: ni siquiera el armadillo es mencionado. Esta invisibilidad de la fauna indiana tendría sus consecuencias, ya que, precisamente, fueron las disparidades existentes entre los conocimientos heredados de la Antigüedad y las experiencias del Nuevo Mundo las que forzaron una reorganización de los modelos epistemológicos y un abandono de los autores clásicos ${ }^{70} \ldots$... contrario, justamente, de nuestros autores.

La taxonomía empleada, por otro lado, es la que está vigente en estos tiempos, relacionada básicamente con criterios habitacionales y no morfológicos, que tendrán que esperar hasta la obra de Linneo. Bernardino de Sahagún, por ejemplo, en su Historia general de las cosas de Nueva España, nos habla de animales (por las descripciones se ve que eran terrestres y en general cuadrúpedos), aves, animales de agua (comprende peces, algunos crustáceos y quelonios, pero también el armadillo y la iguana, seguramente porque eran comestibles y porque no sabía bien donde incluirlos), animales de agua no comestibles (caimanes, culebras de agua), serpientes e insectos ${ }^{71}$. Conrad Gessner, que publicara su obra a mediados del siglo XVI, dedica varios tomos a los cuadrúpedos, las aves, y los animales acuáticos. Y Jan Jonston, en su Historia naturalis (1650), nos habla sucesivamente de cuadrúpedos, serpientes y dragones, insectos, animales acuáticos, peces y cetáceos, y aves. Incluso Linneo, en la primera edición de su Systema naturae (Leyden, 1735), nos sigue hablando de los quadrupedia, y no será hasta la edición de 1758 (considerada el punto de partida de la nomenclatura zoológica) cuando mencione a los mammalia (mamíferos), acompañados por las aves, los amphibia (donde incluye también los reptiles), los pisces, los insecta (los artrópodos) y los vermes (los restantes invertebrados). Clasificación que, todo hay que decirlo, no fue aceptada automáticamente: el conde de Buffon en su magna Historia natural general y particular (1746-1788), todavía nos sigue hablando de los cuadrúpedos.

Covarrubias tampoco refleja un particular afecto hacia el mundo animal, visto fundamentalmente bajo un prisma utilitario y al servicio de las necesidades del ser humano. Desde luego, no será el único. Martínez de Espinar define la caza como "una acción de buscar seguir y perseguir a las fieras o a las aves para rendirlas y sujetarlas el hombre a su dominio" (lib. 1, cap. 1); en tanto para Calvo Pinto "no es

\footnotetext{
${ }^{70}$ BARRERA-OSORIO, A., Experiencing nature, p. 103.

${ }^{71}$ ALVAREZ PELAEZ, Raquel, La conquista, pp. 91-92.
} 
otra cosa que seguir en el campo las aves y fieras que están libres para reducirlas a nuestro dominio y servicio" (cap. 1), por lo que el señorío humano sobre los animales parece completamente legitimado. Aunque hay excepciones, que nos dan una imagen mucho más cariñosa, y que no hacen más que heredar una de las tradiciones de la escolástica, destacando el benedictino Francisco de Blasco Lanuza, que en su Patrocinio de ángeles y combate de demonios nos habla del "sumo cuidado que Dios tiene de socorrer las necesidades de las aves y peces" (lib. I, Pimera parte, c. II) y de "las armas y astucias que da a los animales para defender sus vidas" (lib. 1, Primera parte, c. III), llegando incluso a sostener que los animales tienen ángel de la guarda ("Que cualquier especie de animales y plantas y elementos tiene para su defensa y conservación ángeles, por Divina Providencia consignados", Lib. I, Segunda parte, c. XVIII), ya que sobre ellos también se extiende la Providencia divina.

El Tesoro de la lengua castellana se inserta plenamente en lo que Ashworth ${ }^{72}$ denomina visión emblemática de la naturaleza, en la cual los animales eran un elemento más de un intrincado lenguaje de metáforas, símbolos y emblemas, constituyendo un factor primordial en la historia natural del Renacimiento, y en la que confluyen varias tradiciones, a saber, la jeroglífica de Horapolo, la anticuaria (que se basaba en las monedas y medallas de la Antigüedad), la esópica, la mitológica de Ovidio, Natale Conti o Vincento Cartari, la adágica de Erasmo y la emblemática de Alciato (por cierto, todas estas fuentes son conocidas por Covarrubias). En esta visión emblemática, si uno quería estudiar un animal, debía ver el significado de su nombre, las asociaciones que tenía, qué simbolizaba para paganos y cristianos, qué animales tenían simpatías o afinidades con la especie en cuestión, y su posible conexión con estrellas, plantas, animales, números o cualquier otra cosa. La anatomía, la psicología y la taxonomía pueden ser el corazón de la moderna zoología, pero ello no era así en la época de Covarrubias. Como muy bien dijera Foucault, los signos formaban parte de las cosas, y no se habían convertido en meros modos de representación: al fin y al cabo, Aldrovandi no era ni mejor ni peor observador que Buffon, y parece saber muchas más cosas que Jan Jonston, lo único que ocurre es que la perspectiva epistemológica es diferente ${ }^{73}$. Mutatis mutandis, Covarrubias es más rico en contenido que el Diccionario de Autoridades ${ }^{74}$, cuya publicación se iniciara en 1726, y que parece responder a un espíritu radicalmente diferente. Ciertamente, el bagaje zoológico se ha enriquecido con nuevas especies, procedentes fundamentalmente del continente americano, como el armadillo, "animal pequeño en las Indias cubierto de conchas" (vol. 1, p. 393), o el manato (o manatí), "especie de tiburón, que se cría en el mar Indico...la hembra tiene dos grandes tetas" (vol. 2, p. 471). Pero la poda de los elementos simbólicos y morales ha sido evidente: el águila,

${ }^{72}$ ASHWORTH, William B. Jr., "Natural History and the Emblematic World”, LINDBERG, D.C., y WESTMAN, R. S., Reappraisals of the Sciebntific Revolution, Cambridge U.P., 1990. Reeditado en HELLYER, M., The scientific revolution: the essential readings, Blackwell, 2003.

${ }^{73}$ Sobre los presupuestos de la historia natural que nace a partir de mediados del Seiscientos, FOUCAULT, Michel, op. cit., pp. 128ss. La comparación entre Aldrovandi y Buffon, en pp. 47-48.

${ }^{74}$ Consultada la edición de la madrileña editorial Gredos publicada en 1984. 
que tan florida literatura generara al respecto, es descrita como "ave bien conocida, y reina de todas las otras" (vol. 1, p. 130). Y el elephante (elefante), tan querido por Covarrubias y su ilustre predecesor Plinio, se ha visto reducido a la condición de "animal cuadrúpedo, y el mayor en cuerpo de todos los animales" (vol. 2, p. 376).

Todavía en el siglo XVIII la visión simbólica sigue funcionando (lo que es congruente con el hecho de que, según la reciente crítica, la Revolución científica no fue tan revolucionaria como se ha dicho) ${ }^{75}$, y la obra de Buffon (el maestro de la nueva fábula, como se le ha dado en llamar), es muy ilustrativa al respecto, como muestra su plasmación de simpatías y antipatías en la descripción de especies tales el lobo o el elefante ${ }^{76}$. Pero ello no impide que las prioridades sean distintas, y el renovado interés por la Historia natural que observamos en la España de finales del siglo XVIII ${ }^{77}$, cuya manifestación más llamativa serán las grandes expediciones científicas $^{78}$ amparadas por una monarquía deseosa de obtener prestigio cultural, se inscribirá en unos parámetros completamente diferentes: la consulta de obras como la de Juan Félix de Azara, por ejemplo, nos reflejará una gran preocupación por la descripción morfológica, en la cual las mediciones matemáticas constituyen un elemento fundamental, todo ello en pro de una pretendida objetividad cuya búsqueda, tal como han demostrado recientemente Lorraine Daston y Peter Galison, se ha revelado como una quimera ${ }^{79}$. Aunque la visión simbólica, empero, nunca ha desaparecido del todo, es más, conoció en el siglo XX una formidable revitalización gracias al poder del cine, la televisión, y el comic. Seguimos contemplando a los animales, en muchas ocasiones, en términos de símbolos, virtudes y defectos, lo cual, al fin y al cabo, era lo que hacía Covarrubias.

${ }^{75}$ SHAPIN, Steven, The scientific revolution, Chicago U.P., 1996, trad. Esp. La revolución cientifica: una interpretación alternativa, Barcelona, Paidós, 2000.

${ }^{76}$ ROBBINS, Louise E., Elephant slaves.

${ }^{77}$ Algunas acotaciones sobre autores finidieciochescos en JOSA LLORCA, J., "La historia natural en la España del siglo XIX: botánica y zoología", Ayer, 7, 1992.

${ }^{78}$ Un ejemplo en GONZALEZ CLAVERAN, V., La expedición científica de Malaspina en Nueva España 1789-1794, México, 1988.

${ }^{79} \mathrm{El}$ argumento de estos autores es que el concepto de objetividad es el producto de unas determinadas circunstancias históricas (fue esbozado en la comunidad científica a mediados del siglo XIX) y una pretensión inasequible. El ideal de un trabajo no contaminado por la subjetividad del autor y las circunstancias en las cuales se produce es, sencillamente, imposible. Cfr. DASTON, Lorraine, y GALISON, Peter, Objectivity, Boston, Zone Books, 2007. 